\title{
Dendrimers and Polyamino-Phenolic Ligands: Activity of New Molecules Against Legionella pneumophila Biofilms
}

\section{OPEN ACCESS}

Edited by:

Tzi Bun Ng,

The Chinese University of Hong Kong,

China

Reviewed by:

Joana Costa,

University of Coimbra, Portugal

Alejandro De Las Penas,

Instituto Potosino de Investigación

Científica y Tecnológica, Mexico

Vishvanath Tiwari,

Central University of Rajasthan, India

*Correspondence:

Elisa Andreozzi

elisa.andreozzi@uniurb.it

Specialty section: This article was submitted to Antimicrobials, Resistance

and Chemotherapy,

a section of the journal

Frontiers in Microbiology

Received: 26 November 2015

Accepted: 23 February 2016

Published: 09 March 2016

Citation:

Andreozzi E, Barbieri F, Ottaviani MF

Giorgi L, Bruscolini F, Manti A, Battistelli M, Sabatini $L$ and Pianetti A (2016) Dendrimers

and Polyamino-Phenolic Ligands: Activity of New Molecules Against Legionella pneumophila Biofilms.

Front. Microbiol. 7:289.

doi: 10.3389/fmicb.2016.00289

\section{Elisa Andreozzi ${ }^{*}$, Federica Barbieri', Maria F. Ottaviani², Luca Giorgi², Francesca Bruscolini ${ }^{1}$, Anita Manti ${ }^{1}$, Michela Battistelli ${ }^{1}$, Luigia Sabatini ${ }^{1}$ and Anna Pianetti ${ }^{1}$}

\footnotetext{
${ }^{1}$ Department of Biomolecular Sciences, University of Urbino Carlo Bo, Urbino, Italy, ${ }^{2}$ Department of Pure and Applied Sciences, University of Urbino Carlo Bo, Urbino, Italy
}

Legionnaires' disease is a potentially fatal pneumonia caused by Legionella pneumophila, an aquatic bacterium often found within the biofilm niche. In man-made water systems microbial biofilms increase the resistance of legionella to disinfection, posing a significant threat to public health. Disinfection methods currently used in water systems have been shown to be ineffective against legionella over the long-term, allowing recolonization by the biofilm-protected microorganisms. In this study, the antibiofilm activity of previously fabricated polyamino-phenolic ligands and polyamidoamine dendrimers was investigated against legionella mono-species and multi-species biofilms formed by $L$. pneumophila in association with other bacteria that can be found in tap water (Aeromonas hydrophila, Pseudomonas aeruginosa, Escherichia coli, Klebsiella pneumoniae). Bacterial ability to form biofilms was verified using a crystal violet colorimetric assay and testing cell viability by real-time quantitative PCR and Plate Count assay. The concentration of the chemicals tested as anti-biofilm agents was chosen based on cytotoxicity assays: the highest non-cytotoxic chemical concentration was used for biofilm inhibition assays, with dendrimer concentration 10-fold higher than polyamino-phenolic ligands. While Macrophen and Double Macrophen were the most active substances among polyamino-phenolic ligands, dendrimers were overall twofold more effective than all other compounds with a reduction up to 85 and $73 \%$ of legionella and multi-species biofilms, respectively. Chemical interaction with matrix molecules is hypothesized, based on SEM images and considering the low or absent anti-microbial activity on planktonic bacteria showed by flow cytometry. These data suggest that the studied compounds, especially dendrimers, could be considered as novel molecules in the design of research projects aimed at the development of efficacious anti-biofilm disinfection treatments of water systems in order to minimize legionellosis outbreaks.

Keywords: Legionella pneumophila, biofilm formation, biofilm removal, polyamino-phenolic ligands, dendrimers 


\section{INTRODUCTION}

Legionella genus includes aerobic, motile, gram-negative bacteria that are the etiological agents of legionellosis. The clinical spectrum and severity of the infection ranges from a self-limited, acute flu-like illness, to an atypical severe form of pneumonia called Legionnaires' disease, characterized by a high mortality rate of $10-15 \%$ (Bartram et al., 2007). The most pathogenic species is Legionella pneumophila, responsible for more than $90 \%$ of described clinical cases (Steinert et al., 2002; Bartram et al., 2007), and strains belonging to serogroup 1 (Sg1) the ones predominantly isolated (Doleans et al., 2004; $\mathrm{Ng}$ et al., 2009). The reason for the higher pathogenicity of L. pneumophila Sg1 is not completely understood; its clinical prevalence appears not to be correlated with predominance in the environment, where non-Sg1 strains show higher recovery percentages. The low non-Sg1 sensitivity of the commonly used diagnostic method could be a reason for Sg1 clinical prevalence, however, previous studies link it to an increased resistance to the alternative serum complement pathway, due to variations in the outer-membrane $\mathrm{O}$-antigen segment of the lipopolysaccharide. Moreover, Sg1 strain Philadelphia was proven to induce bacteraemia and disseminate to other organs in mice, unlike non-Sg1 strains (Khan et al., 2013).

Legionella sp. show ubiquitous distribution, occurring in different natural aquatic environments and artificial water systems (Doleans et al., 2004). Legionella transmission mostly occurs via aerosols generated by several potential sources such as air conditioning and hot water systems, cooling towers, humidifiers and shower heads (Doleans et al., 2004; Osawa et al., 2014). Legionella virulence is due to its ability to infect and grow in macrophages and its environmental persistence largely depends on the ability to proliferate in protozoa, especially in amoebae of genera Acanthamoeba and Hartmannella (Doleans et al., 2004; Messi et al., 2013).

Legionella sp. can survive in natural and man-made water environments as planktonic cells or as surface-associated cells, embedded in an extracellular polysaccharide matrix, forming mixed microbial biofilms (Bartram et al., 2007; Declerck et al., 2009; Stewart et al., 2012). Biofilm formation allows nutrient distribution and sharing of genetic material, facilitates intercellular communications by signal molecules and supplies cell protection from environmental stresses (Watnick and Kolter, 2000) and from biocides or disinfectant treatments that would inactivate free-floating microorganisms (Sanli-Yurudu et al., 2007; Bridier et al., 2011). Biofilms positively influence the persistence of Legionella in water systems and they may enhance the virulence of the bacteria inside the host. Khweek et al. (2013) found that biofilm-derived legionellae were able to avoid the phagosome-lysosome fusion in murine macrophages and to proliferate more rapidly in host cells in contrast to planktonic bacteria. Moreover, the presence of protozoa, such as amoebae, in water systems increases bacterial resistance to antimicrobial agents, acting as hosts for legionella replication and protectors within the intracellular niche (Declerck et al., 2009; Lau and Ashbolt, 2009). Intraamoeba grown Legionella sp. appear to be even more pathogenic than the free-living form as they were found to be more invasive in several human cell lines (Lau and Ashbolt, 2009).

In order to prevent legionellosis outbreaks, different disinfection methods (water heating, ultraviolet radiation, chlorination, monochloramine, ozonation, copper and silver ionization, peroxides) have been used to eliminate legionellae or at least control their growth in water supplies (Miyamoto et al., 2000; Levin, 2009; Jakubek et al., 2013). However, most of the physical and chemical treatments have been shown not to be effective over a long time, mainly because of their inability to penetrate the biofilm, which strengthens the microbial tolerance to biocides, thereby favoring bacterial regrowth after decontamination (Ditommaso et al., 2005; Iatta et al., 2013). Even though monochloramine was found to cause a significant decrease of L. pneumophila in a nuclear power plant cooling circuit, the presence of biofilm allowed the re-colonization of the system when the treatment was interrupted (Jakubek et al., 2013). Furthermore, the most clinically relevant strains, L. pneumophila Sg 1, were shown to be the most resistant serogroup to chlorination in several studies, as they might develop or better adapt to protective biofilms (Cooper and Hanlon, 2010; Iatta et al., 2013).

Removal of biofilms means elimination of one of the main sources of recontamination after water system treatment and could be helpful to obtain a better performance of the commonly used disinfection methods that are effective on planktonic microorganisms but not on the sessile counterpart. Discovery and implementation of new potential and effective disinfection strategies is a major but essential challenge to minimize Legionella presence and consequently reduce legionellosis risk to public health. This goal could be achieved testing new molecules that are active against bacteria resistant to traditional biocides, as referred by Tiwari et al. (2015), and also active in biofilm control. Some anti-biofilm techniques have been developed and proposed, combining mechanical with physical or chemical processes. It is also suggested that addition of enzymatic molecules contributes to biocide activity improvement through destruction of the polysaccharide matrix (de Carvalho, 2007). However, new studies are necessary to improve the efficiency of biofilm removal. In order to test compounds that could be thought as novel molecules in the development of new and not only temporary disinfection strategies, we investigated the ability of polyamidoamine (PAMAM) dendrimers and polyamino-phenolic ligands to interfere with biofilms.

PAMAM dendrimers are repetitively branched molecules typically symmetric around the central core, where the number of ramifications determines the number of generations. The surface of PAMAM dendrimers exhibit carboxy (half-generation, e.g., G0.5 dendrimer) or amino groups (full-generation, e.g., G2 dendrimer), whose number increases with the number of generations (Tomalia et al., 2012). Dendrimers have been studied so far to act as drugs, drug carriers, vehicle of biological materials and antimicrobial agents (Chen and Cooper, 2000; Ottaviani et al., 2000, 2004; Klajnert et al., 2006; Tülü and Ertürk, 2012). Dendrimers could also be very good candidates 
to interact with and then remove biofilms since they offer a large number of external surface groups controlling most of the physical properties and able to contemporaneously interact with active sites (Zarena and Gopal, 2013). Furthermore, they show complete solubility in water and can be charged on the surface to promote the interaction with the bacterial wall (Chen and Cooper, 2000; Tülü and Ertürk, 2012) or with biofilm molecules, interfering with chemical bonds present in the matrix. Dendrimers have also been functionalized with biocide functional groups able to interact with specific bacterial targets (Chen and Cooper, 2000; Lazniewska et al., 2012). For example, dendrimeric peptides inhibited E. coli viability in both planktonic and biofilm states in a dose-dependent manner at concentrations ranging from 5 to $40 \mu \mathrm{M}$ (Hou et al., 2009). Johansson et al. (2008) also referred that multivalent fucosylpeptide dendrimers caused a complete inhibition of biofilm formation $\left(\mathrm{IC}_{50} \sim 10 \mu \mathrm{M}\right.$ ) and dispersion of already established biofilms in Pseudomonas aeruginosa, without affecting bacterial growth.

Polyamino-phenolic ligands are polyfunctional molecules containing one or more phenol, biphenol, naphthol, cathecol, and other hydroxy-aryl groups connected to a polyamine skeleton with linear or macrocyclic topology (Ambrosi et al., 2008). Due to the acidity of the phenol moieties and to the basicity of the amine groups, these compounds are amphiprotic and in aqueous solution can be present in different protonation forms depending on the $\mathrm{pH}$, most of them with amphi-ionic character. Polyamino-phenolic ligands are able to interact with several substrates as cations (including ammonium salts and metal ions), anions, and neutral species with strong hydrogen bond donors, like carbohydrates, urea derivatives, peptides and other highly polar biomolecules (Steed and Atwood, 2009).

Therefore, considering that dendrimers have already been shown acting as anti-microbial agents both in planktonic and biofilm states (Chen and Cooper, 2000; Tülü and Ertürk, 2012; Zarena and Gopal, 2013), they were selected in this study to experiment their action in the prevention and control of biofilms formed by L. pneumophila. Furthermore, previously fabricated polyamino-phenolic ligands (Ambrosi et al., 2008) were chosen considering that the potential role of amphiprotic molecules in the inhibition of biofilm is already well known (Banin et al., 2006; Chang et al., 2012).

\section{MATERIALS AND METHODS}

\section{Sampling and Isolation}

Putative L. pneumophila strains were isolated from hot water of several accommodation facilities (hotels, residences and camping sites) in Pesaro-Urbino area (Italy) and verified as belonging to the genus Legionella according to Italian legislation (Guidelines for prevention and control of legionellosis, 2000).

Aeromonas hydrophila, Pseudomonas aeruginosa, Klebsiella pneumonia, Escherichia coli strains were isolated from the environment and identified as previously reported (Ottaviani et al., 2011; Sabatini et al., 2013; Boi et al., 2015).

\section{Molecular and Serological Identification}

Isolated Legionella strains were cultured on Charcoal Yeast Extract (CYE) agar added with Legionella Buffered Charcoal Yeast Extract (BCYE) growth supplement (BCYE agar) (Liofilchem, Roseto degli Abruzzi, Italy). Genomic DNA was extracted using DNeasy Blood and Tissue Kit (Qiagen, Hilden, Germany), according to the manufacturer's instructions. The strains were confirmed as L. pneumophila by a multiplex species-specific PCR assay (Qasem et al., 2008), using a slight modified protocol. The sequence of Legionella genus-specific primers (L5SL9 - L5SR93) and L. pneumophila-specific primers (LmipL920 - LmipR1548), the target gene and the expected size of amplified DNA were previously reported. The reaction mixture $(45 \mu \mathrm{L}+5 \mu \mathrm{L}$ of sample DNA) consisted of $0.15 \mu \mathrm{M}$ of L5SL9 and L5SR93 primers, $0.5 \mu \mathrm{M}$ of LmipL920 and LmipR1548 primers, $200 \mu \mathrm{M}$ dNTPs, $1.5 \mathrm{mM} \mathrm{MgCl}_{2}, 1 \mathrm{X}$ PCR Buffer, and 1.25 U Hot-Rescue DNA polymerase (all from Diatheva, Fano, Italy). Amplification of target DNA was performed in a MultiGene Gradient Termal Cycler (Labnet International, Edison, NJ, USA): initial denaturation at $95^{\circ} \mathrm{C}$ for $10 \mathrm{~min}$ followed by 35 cycles $\left(1 \mathrm{~min}\right.$ at $95^{\circ} \mathrm{C}, 1 \mathrm{~min}$ at $51^{\circ} \mathrm{C}$, $1 \mathrm{~min}$ at $72^{\circ} \mathrm{C}$ ) and final extension at $72^{\circ} \mathrm{C}$ for $10 \mathrm{~min}$.

In order to distinguish L. pneumophila Sg 1 from serogroups 2-15, a serological test was performed using Legionella Latex Kit (Liofilchem, Roseto degli Abruzzi, Italy), a rapid agglutination test.

Stock cultures were stored at $-80^{\circ} \mathrm{C}$ in Brain Heart Infusion Broth (Oxoid, Basingstoke, UK) containing glycerol at 20\% (v/v) until they were used.

\section{Biofilm Assay}

Legionella pneumophila strains were tested for their ability to form biofilm in different media: tap chlorinated water, filtered tap chlorinated water, spring water, filtered spring water and filtered Legionella Buffered Yeast Extract (BYE) broth, composed by $10 \mathrm{~g} / \mathrm{L}$ Yeast Extract (Liofilchem, Roseto degli Abruzzi, Italy), $10 \mathrm{~g} / \mathrm{L}$ ACES Buffer, $1 \mathrm{~g} / \mathrm{L}$ alpha-ketoglutaric acid, $0.4 \mathrm{~g} / \mathrm{L}$ L-cystein hydrochloride monohydrate, $0.25 \mathrm{~g} / \mathrm{L}$ Iron (III) pyrophosphate hydrate (all from Sigma-Aldrich, St Louis, MO, USA) (before filtering, $\mathrm{pH}$ was adjusted to 6.9 with $\mathrm{KOH})$. Water was used to set up a condition very similar to that in water systems. Two types of water were employed to highlight the different bacterial ability to produce biofilm in chlorinated and non-chlorinated water. Filtered water $(0.2 \mu \mathrm{m}$ pore size filter) was also used to avoid the interference of autochthonous microorganisms that could make the results hard to interpret and reproduce. BYE broth was used to verify if water could be a limitation for Legionella biofilm formation.

The biofilm formation assay was performed using a slight modification of a method reported by Baldassarri et al. (2001). Briefly, Legionella strains grown on BCYE agar were harvested using the waters and the broth described above. Single strain cultures were then centrifuged at $3000 \mathrm{rpm}$ for $30 \mathrm{~min}$ and the pellet was resuspended in the same substrates to obtain an absorbance $(600 \mathrm{~nm})$ of $0.7\left(9 \times 10^{8} \mathrm{CFU} / \mathrm{mL}\right)$. The suspensions were inoculated in 96-well polystyrene plates $(200 \mu \mathrm{L} /$ well $)$. After 
3, 6, and 9 days of incubation at $37^{\circ} \mathrm{C}$ in wet atmosphere, planktonic cells were removed and wells were gently rinsed with sterile distilled water to eliminate non-adhering bacteria. Adhered bacteria were fixed at $80^{\circ} \mathrm{C}$ for $10 \mathrm{~min}$. After staining at room temperature for 10 min with Hucker's crystal violet, the dye was removed and the wells were washed two times. Hence, $200 \mu \mathrm{L} 95 \%(\mathrm{v} / \mathrm{v})$ ethanol were added in each well to dissolve Hucker's crystal violet. Biofilm formation was quantified by measuring the absorbance of the solubilized dye at $570 \mathrm{~nm}$, using a plate reader (Thermo Electron Corporation, Vantaa, Finland). Strains were identified as strong (OD > 0.240), weak $(0.120<\mathrm{OD}<0.240)$ and non- $(\mathrm{OD}<0.120)$ biofilm producers. ATCC 35984, ATCC 35983, and ATCC 12228 Staphylococcus epidermidis strains were used as controls for strong, weak and non-biofilm producers (Zhang et al., 2003; Taj et al., 2012). The major biofilm producer strain was used for further analysis.

Pseudomonas aeruginosa, A. hydrophila, E. coli, and K. pneumoniae strains were simultaneously tested for their ability to form biofilm over 3 days in filtered tap chlorinated water at $37^{\circ} \mathrm{C}$ in wet atmosphere, each strain alone and in association with L. pneumophila major biofilm producer. Monospecies biofilms were formed as described for Legionella strains; two-species and five-species biofilms were prepared using the same amount of each species to reach the final concentration of $9 \times 10^{8} \mathrm{CFU} / \mathrm{mL}(200 \mu \mathrm{L} /$ well $)$.

\section{$16 S$ rRNA Gene Sequencing}

The higher biofilm producer strain of $L$. pneumophila was characterized by sequencing of the $16 \mathrm{~S}$ rRNA gene. PCR amplification of the 16S rRNA gene was performed by adding $5 \mu \mathrm{L}$ of the extracted DNA to $45 \mu \mathrm{L}$ of the reaction mixture: $0.8 \mu \mathrm{M}$ of 27F (DeLong, 1992) and 1492R (Lane, 1991) primers, $100 \mu \mathrm{M}$ dNTPs, 1.5 mM MgCl 2 , 1X PCR Buffer, 0.075 U HotStart Taq DNA polymerase (all from Qiagen, Hilden, Germany). PCR was carried out on iCycler BioRad Thermal Cycler as decribed by Kahlisch et al. (2010). PCR products were purified by MinElute PCR Purification Kit (Qiagen, Hilden, Germany) and used as a template for sequencing with Big Dye Terminator Sequencing Kit (Applied Biosystems, Foster City, CA, USA), using the same primers as those used in the PCR. Sequencing PCR products were purified by DyeEx 2.0 Spin Kit (Qiagen, Hilden, Germany), following the manufacturer's instructions, and sequenced on ABI Prism 3100 Genetic Analyser. Forward and reverse sequences were analyzed and assembled using Sequencher 5.2.4 (Gene Codes Corporation, Ann Arbor, MI, USA) and blasted against Ribosomal Database Project (Cole et al., 2013).

\section{Assessment of Bacterial Cell Viability in Multi-Species Biofilms}

In order to assess cell viability of $L$. pneumophila in multispecies biofilms, a reverse-transcription quantitative real-time PCR (RTqPCR) assay was used to quantify transcriptionally active (viable) Legionella cells, as described by Andreozzi et al. (2014). Briefly, a standard calibration curve was built using appropriate dilutions $\left(1 \times 10^{-5}\right.$ to $\left.1 \times 10^{-8} \mathrm{ng} / \mu \mathrm{L}\right)$ of a purified 5S rDNA amplicon obtained from a PCR reaction performed using extracted DNA of L. pneumophila grown on BCYE agar. PCR, RTqPCR and melt curve analysis were conducted as previously reported. Two-species and five-species biofilms were grown in filtered tap water for 3 days in 12well plates containing $2 \mathrm{~mL} /$ well bacterial suspensions, with the same amount of each species to reach the final concentration of $9 \times 10^{8} \mathrm{CFU} / \mathrm{mL}$. After incubation at $37^{\circ} \mathrm{C}$, planktonic cells were removed and wells were washed. Adherent biofilm cells were harvested in sterile distilled water, obtaining a final $\mathrm{OD}_{600}$ of 1.0. RNA was extracted using Total RNA Purification Kit (Norgen Biotek, Thorold, ON, Canada), and retrotranscription of RNA in cDNA was carried out by QuantiTect Reverse Transcription Kit (Qiagen, Hilden, Germany), according to the manufacturer's instructions. RTqPCR reactions containing undiluted and diluted $(1: 10,1: 100,1: 1000)$ cDNA from every mixed biofilm were run together to account for potential qPCR inhibition. Experiments were executed in triplicate for each reaction and repeated three times in order to assess repeatability and reproducibility of the standard curve. The coefficient of variation (CV) and the limit of detection (LOD) were determined. Transcriptionally active Legionella cell number/mL was calculated for every mixed biofilm as previously described.

The presence of $P$. aeruginosa, A. hydrophila, E. coli, and K. pneumoniae viable cells in mixed biofilms was detected by performing a Plate Count assay. Serial 10-fold dilutions of the same two-species and five-species biofilm samples used for RNA extraction were prepared in Phosphate Buffer Saline (PBS) and five $10 \mu \mathrm{L}$ drops of each dilution were placed onto selective media: Cetrimide Agar, Mac Conkey Agar (both from Liofilchem, Roseto degli Abruzzi, Italy) and m-Aeromonas Selective Agar Base (Havelaar) (Biolife, Milano, Italy). CFU count was performed after incubation at $37^{\circ} \mathrm{C}$ for $24 \mathrm{~h}$.

\section{Chemical Compounds}

Five polyamino-phenolic ligands (Macrophen, Double Macrophen, Bisom, Dimo, Bfden), synthesized by the Laboratory of Supramolecular Chemistry (Department of Pure and Applied Sciences, University of Urbino) (Ambrosi et al., 2008), and two PAMAM dendrimers half-generation (G0.5) and secondgeneration (G2), a gift from Prof. Donald A. Tomalia, were used to inhibit biofilm formation and promote biofilm degradation (Figure 1).

\section{Cytotoxicity Test}

INT 407 (ATCC CCL-6) and HeLa (ATCC CCL-2) cell lines were used for cytotoxicity assays. $100 \mu \mathrm{L}$ cell suspensions were seeded at numbers of $1 \times 10^{5} \mathrm{cell} / \mathrm{mL}$ on 96 -well plates that were incubated for $24 \mathrm{~h}$ at $37^{\circ} \mathrm{C}$ in $5 \% \mathrm{CO}_{2}$. Then the chemicals were added to each well to obtain different final concentrations $(0.01,0.1,0.5,1.0,5.0 \mathrm{mM})$. Chemical effect was evaluated after 24 and $48 \mathrm{~h}$ of incubation. Cell viability was assessed by 3-(4,5-dimethylthiazol-2-yl)-5-(3-carboxymethoxyphenyl)-2(4-sulfophenyl)-2H-tetrazolium (MTS) assay using CellTiter 96 


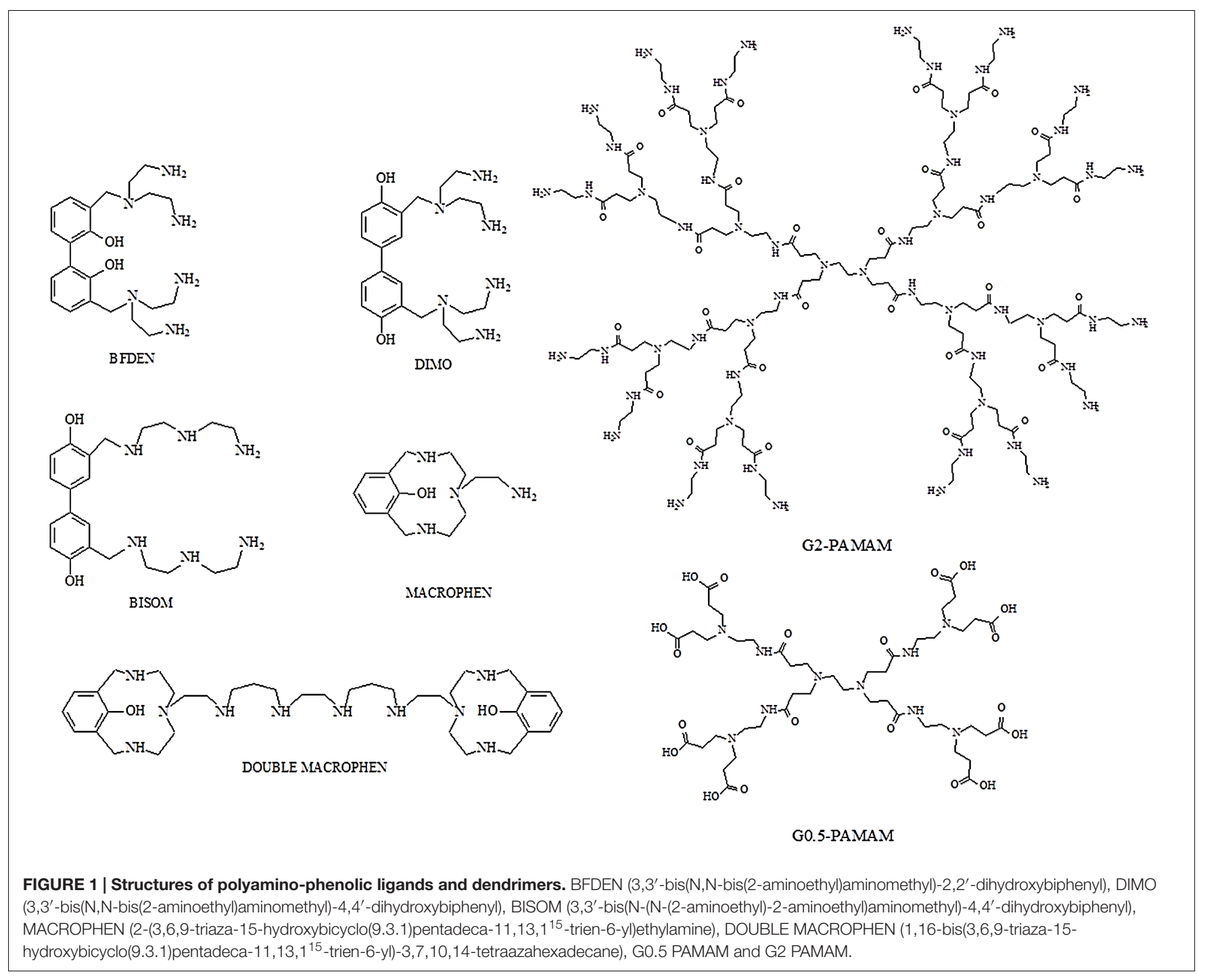

AQueous Non-radioactive Cell Proliferation Assay (Promega, Madison, WI, USA), adding $20 \mu \mathrm{l}$ of the MTS/PMS (phenazine methosulfate) solution to each well. MTS is reduced by dehydrogenase enzymes of living cells into a soluble purple formazan product. After $2.5 \mathrm{~h}$ of incubation, absorbance of formazan, proportional to the number of viable cells, was measured at $492 \mathrm{~nm}$ by the plate reader previously mentioned. Cells without chemicals were used as positive control (PC). The percentage of treated cell viability was evaluated setting the control to $100 \%$.

\section{Anti-Biofilm Activity of Chemicals}

The activity of chemicals was tested on the biofilm formed by the highest L. pneumophila producer strain and on multispecies biofilms formed by different microorganism associations (L. pneumophila/P. aeruginosa, L. pneumophila/A. hydrophila, L. pneumophila/E. coli, L. pneumophila/K. pneumoniae, L. pneumophila/P. aeruginosa/A. hydrophila/E. coli/K. pneumoniae). These bacteria can exist in tap water and could interact with Legionella biofilm formation. Biofilm assay was carried out as described above.

\section{Biofilm Degradation}

Bacterial cultures in tap water $\left(9 \times 10^{8} \mathrm{CFU} / \mathrm{mL}\right)$ were inoculated in 96-well polystyrene plates $(200 \mu \mathrm{L} /$ well $)$; legionella monospecies and mixed biofilms were prepared as described above. The plates were incubated for 3 days at $37^{\circ} \mathrm{C}$ in wet atmosphere to allow biofilm formation. After incubation, planktonic cells were removed and wells were delicately rinsed with sterile distilled water to eliminate non-adhering bacteria. Then polyaminophenolic ligands and PAMAM dendrimers were diluted in tap water ( 0.1 and $1.0 \mathrm{mM}$ final concentration respectively) and added to the wells. The plates were incubated at $37^{\circ} \mathrm{C}$ for other 3 days to let the substances act on the already formed biofilms.

\section{Biofilm Inhibition}

Ten microliter/well polyamino-phenolic ligands $(0.1 \mathrm{mM}$ final concentration) and $10 \mu \mathrm{L} /$ well PAMAM dendrimers ( $1 \mathrm{mM}$ final concentration) were added to the 96 -well polystyrene plates 
inoculated with bacterial cultures in tap water $\left(9 \times 10^{8} \mathrm{CFU} / \mathrm{mL}\right)$ $(190 \mu \mathrm{L} /$ well $)$ at the inoculum time to test biofilm inhibition activity of the chemicals over 3-day contact time.

Afterward, biofilm degradation and inhibition were evaluated by measuring the absorbance with the plate reader, as described above. Wells containing bacteria without chemical compounds were used as PC. Chemical activity was expressed as the percentage of biofilm reduction relative to the untreated control biofilm.

\section{Planktonic Microbial Cell Viability after Chemical Treatment}

In order to determine if anti-biofilm activity of the chemicals was due to their microbicidal action or to direct interaction with the biofilm matrix, antimicrobial activity was determined on planktonic bacteria.

Microbial viability after compound treatments was tested on planktonic bacteria by flow cytometric analyses with a FACScalibur (Becton Dickinson, Milan, Italy) equipped with an Argon Ion Laser set at $15 \mathrm{mV}$ and tuned to an excitation wavelength of $488 \mathrm{~nm}$. Chemical microbicidal activity on freefloating microorganisms was evaluated: bacterial suspensions in PBS $\left(9 \times 10^{8} \mathrm{CFU} / \mathrm{mL}\right)$ were treated with chemicals at the concentration used for biofilm experiments and incubated at $37^{\circ} \mathrm{C}$ for $24 \mathrm{~h}$ with agitation at $150 \mathrm{rpm}$, to avoid cell adhesion to flask bottom. Bacterial suspensions in PBS without chemicals were used as negative controls, while bacteria treated with $50 \mathrm{mg} / \mathrm{L}$ chlorine were used as PCs. To detect cell viability, bacterial cells were stained for $15 \mathrm{~min}$ with SYBR Green I (1:10000 final concentration) and Propidium Iodide (PI, $1 \mu \mathrm{g} / \mathrm{mL}$ final concentration) (both from Life Technologies, Waltham, MA, USA), fluorochromes with a high affinity for nucleic acids. Then cells were fixed in paraformaldehyde ( $4 \%$ final concentration) for $1 \mathrm{~h}$, washed by centrifugation (3500 rpm for $15 \mathrm{~min}$ ) and suspended in PBS. Cell count was performed by adding Cytocount ${ }^{\mathrm{TM}}$ counting beads (DakoCytomation, Denmark) to the stained samples before processing by flow cytometry (Manti et al., 2011). Multi-parametric analyses were performed on both scattering signals (FSC, SSC), and FL1 to detect SYBR Green I fluorescence and FL3 to detect PI fluorescence. Three populations were evidenced in dot plots: viable cells, damaged cells and dead cells. All parameters were collected in logarithmic scale. All data were statistically analyzed with Cell Quest software.

\section{Scanning Electron Microscopy (SEM)}

The successful biofilm formation by the major biofilm producer Legionella strain and the anti-biofilm activity of dendrimers were confirmed by electron microscopy. The strain grown on BCYE agar was harvested in filtered tap water as described above. One mililiter suspension adjusted at concentration of $9 \times 10^{8} \mathrm{CFU} / \mathrm{mL}$ with or without dendrimers $(1 \mathrm{mM})$ was inoculated in 24-well plate with coverslips. After 3 days of incubation at $37^{\circ} \mathrm{C}$ in wet atmosphere, non-adhering bacteria were removed by gently washing. Adhering bacteria growing on coverslips, were fixed with $2.5 \%$ glutaraldehyde in $0.1 \mathrm{M}$ phosphate buffer ( $\mathrm{pH}$ 7.3) for $1 \mathrm{~h}$. The monolayer was washed and postfixed with $1 \% \mathrm{OsO}_{4}$ in the same buffer for $1 \mathrm{~h}$. A progressive alcohol dehydration was performed, followed by specimen critical point drying. After mounting on conventional SEM stubs by means of silver glue, slides were gold sputtered (Battistelli et al., 2005). Observations were carried out with a Philips 515 scanning electron microscope.

\section{Statistical Analysis}

All experiments were executed in triplicate for each sample and repeated three times. Data were presented as means and standard deviations of the measurements. The reduction of biofilm was analyzed by two-way ANOVA model with respect to microorganisms and different compounds. Experiment wise significance level was fixed at $P<0.05$. All the analyses were performed using Stata 12.1 SE (Stata corporation, College Station, TX, USA).

\section{RESULTS}

\section{Isolation and Identification of Legionella sp.}

Ten putative Legionella strains were isolated from accommodation facilities in Pesaro-Urbino area (Italy) and confirmed as Legionella by biochemical tests. The genus/speciesspecific PCR assay reconfirmed the isolates belonged to Legionella genus and allowed to identify six L. pneumophila strains. Legionella Latex Kit revealed that all L. pneumophila strains were Sg 1.

\section{Microorganism Biofilm Producing Ability}

Overall, $L$. pneumophila biofilm production assays showed that two strains were not able to form any biofilm (OD $<0.120)$, three of them were identified as weak biofilm producers and one strain (L. pneumophila 155) resulted a high biofilm producer $(\mathrm{OD}>0.240)$. Based on the $16 \mathrm{~S}$ rRNA sequence identity level, L. pneumophila strain 155 was classified as L. pneumophila subspecies pneumophila (GenBank accession number: KM657957) and as serogroup 1, after Legionella-specific serotyping assay.

Biofilm producer strains were able to form biofilms in all different growth substrates (data not shown). OD values showed that biofilm formation ability was not decreased when supplying water as growth medium instead of BYE broth. Biofilm formation in spring and tap chlorinated water was similar and not related to the substrate type: weak biofilm producer strains showed mean OD values of $0.144,0.123,0.186$ in spring water and $0.120,0.145,0.172$ in tap water for each strain, respectively; L. pneumophila 155 exhibited mean OD values of 0.265 in spring water and 0.281 in tap water. These data mean that chlorine concentration in tap water was not a limiting factor for biofilm formation. Bacteria were also able to form biofilm in filtered water as much as in unfiltered water $(P>0.05)$. Hence, filtered tap water was chosen as 
substratum for further experiments. Biofilm formation over 6 and 9 days did not show any increase in OD values compared with biofilms over 3 days, therefore 3-day biofilm was chosen for further experiments. L. pneumophila 155 was selected to study biofilm formation in association with the other environmental microorganisms.

Aeromonas hydrophila and K. pneumoniae were classified as weak biofilm producers over 3 days in tap water (mean OD values of 0.123 and 0.131 respectively), whilst they strongly increased biofilm formation when in association with L. pneumophila 155. Instead E. coli and P. aeruginosa were not able to make biofilm on their own $(\mathrm{OD}<0.120)$, but they enhanced the biofilm formation ability in presence of L. pneumophila 155 (Figure 2).

\section{Assessment of Bacterial Cell Viability in Multi-Species Biofilms}

Reverse-transcription quantitative real-time PCR results demonstrated the presence of viable L. pneumophila 155 cells in both two-species and five-species biofilms. In particular, the highest viable cell number was found in L. pneumophila 155/K. pneumoniae biofilm $\left(8.92 \times 10^{7}\right.$ cell $/ \mathrm{mL}$ ), followed by $L$. pneumophila 155/A. hydrophila biofilm $\left(8.71 \times 10^{7} \mathrm{cell} / \mathrm{mL}\right)$ (Table 1$)$. CV intra- and interassay values (not higher than 8.5 and $8.7 \%$ respectively) proved the repeatability and the reproducibility of the assay. The LOD was $3.89 \times 10^{1}$ copies of $5 \mathrm{~S} \mathrm{rDNA} /$ reaction, corresponding to $130 \mathrm{~L}$. pneumophila 155 cells $/ \mathrm{mL}$. The RTqPCR assay displayed an overall efficiency of $91 \%$ and a Pearson's $\mathrm{R}$ coefficient of 0.99 . Melt curve analysis showed a clear and reproducible melting peak between 81.8 and $82.3^{\circ} \mathrm{C}$.
Plate Count assay showed the presence of viable nonlegionella cells in all two-species biofilms (Table 1). However, it was not possible to quantify non-legionella viable strains in five-species biofilms because of the incomplete selectivity of the media, which allowed a widespread growth of $P$. aeruginosa.

\section{Chemical Cytotoxicity}

Cytotoxicity assay was executed to determine the highest noncytotoxic concentration that could be used against the microbial biofilm. Compound concentrations maintaining cell viability higher than $85 \%$ were chosen to test their anti-biofilm activity. A higher threshold than the standard value usually used to establish cytotoxic concentrations $\left(\mathrm{IC}_{50}\right.$ : half maximal inhibitory concentration), was used in this study.

Figure 3 shows the toxicity of polyamino-phenolic ligands and dendrimers in INT 407 (Figure 3A) and HeLa (Figure 3B) cells respectively. Forty eight hour cell treatment exhibited a slightly higher cytotoxicity behavior compared with $24 \mathrm{~h}$ treatment, hence only $48 \mathrm{~h}$ data are illustrated below. Every compound showed nearly the same trend in both cell lines. When treated with polyamino-phenolic ligands, INT 407 and HeLa cells exhibited viability higher than $85 \%$ in the presence of all compounds at concentrations up to $0.1 \mathrm{mM}$. On the other hand, INT 407 cell viability was higher than $85 \%$ only after treatment with Macrophen, Double Macrophen or Bfden at $0.5 \mathrm{mM}(94,95$, and $97 \%$ respectively). Treatment with $0.5 \mathrm{mM}$ Bisom or Dimo led to a INT 407 cell viability of 72 and 58\% respectively. Regarding HeLa cells, only Macrophen showed low cytotoxicity at the $0.5 \mathrm{mM}$ concentration with a cell viability value of $88 \%$, whereas cell viability was below the $85 \%$ threshold with the other compounds. G0.5 and G2 dendrimer treated cells maintained viability values

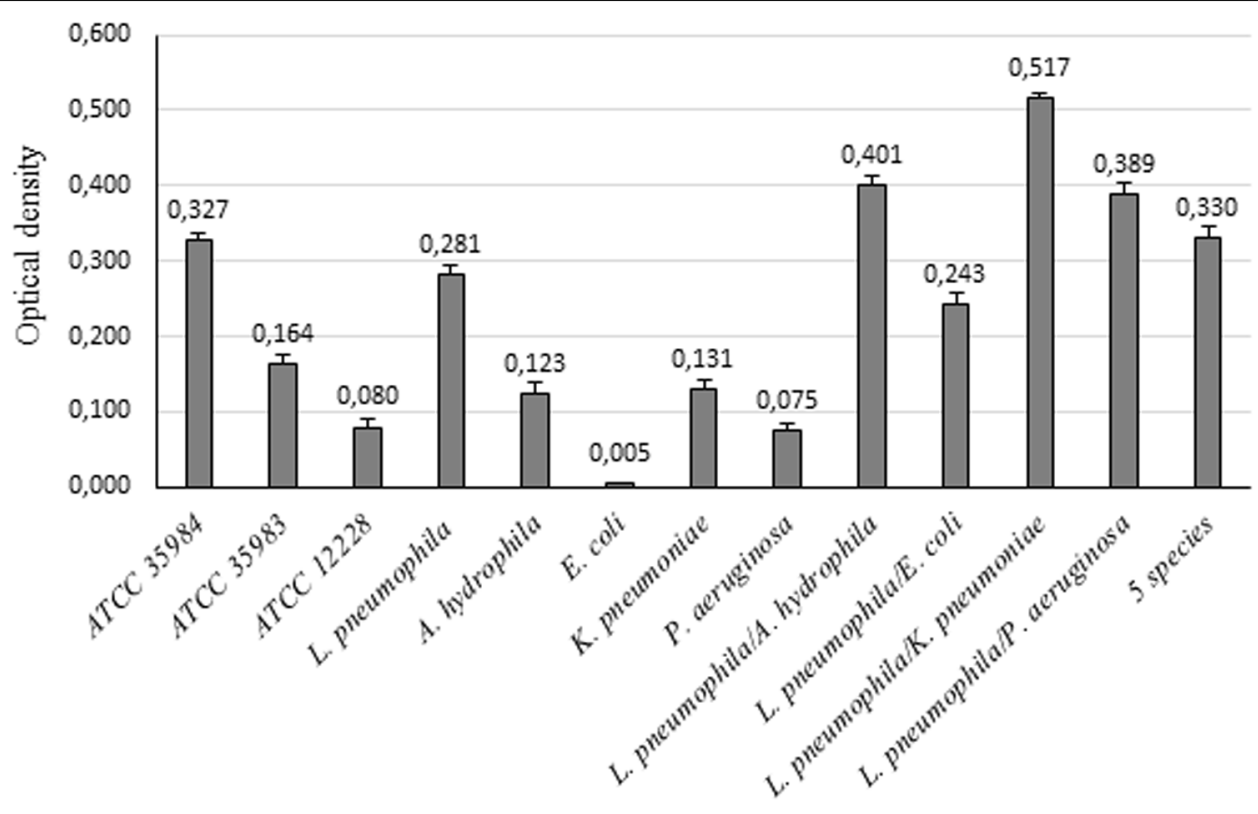

FIGURE 2 | Biofilm formation ability of bacterial strains. OD values of biofilms formed by single bacterial strains and by L. pneumophila 155 in association with environmental strains. ATCC 35984, ATCC 35983, and ATCC 12228 S. epidermidis strains were used as controls for strong, weak and non-biofilm producers. 
TABLE 1 | Count of viable Legionella pneumophila 155 cells and viable non-legionella cells in multi-species biofilms based on quantification of 5SrRNA copies by RTqPCR and on Plate Count assay, respectively.

\begin{tabular}{|c|c|c|}
\hline Biofilms & Trascriptionally active L. pneumophila cells $/ \mathrm{mL}$ & Non-legionella CFU/mL \\
\hline L. pneumophila/A. hydrophila & $8.71 \times 10^{7} \pm 6.92 \times 10^{6}$ & $7.00 \times 10^{8} \pm 1.00 \times 10^{8}$ \\
\hline L. pneumophila/E. coli & $2.02 \times 10^{7} \pm 4.21 \times 10^{6}$ & $5.67 \times 10^{8} \pm 1.53 \times 10^{8}$ \\
\hline L. pneumophila/K. pneumoniae & $8.92 \times 10^{7} \pm 6.30 \times 10^{6}$ & $1.10 \times 10^{9} \pm 1.59 \times 10^{8}$ \\
\hline L. pneumophila/P. aeruginosa & $6.96 \times 10^{7} \pm 6.59 \times 10^{6}$ & $2.11 \times 10^{8} \pm 6.49 \times 10^{7}$ \\
\hline Five-species & $4.98 \times 10^{7} \pm 3.20 \times 10^{6}$ & \\
\hline
\end{tabular}

Cell number is expressed as mean $\pm S D$.

higher than $85 \%$ up to 5 and $1 \mathrm{mM}$ in both cell lines, respectively.

Therefore polyamino-phenolic ligands were used at $0.1 \mathrm{mM}$ and dendrimers were used at $1 \mathrm{mM}$ for further experiments on biofilms.

In addition, polyamino-phenolic ligand concentrations $\leq 0.1 \mathrm{mM}$ and G0.5 dendrimer concentrations $\leq 0.5 \mathrm{mM}$ increased MTS assay OD values of the cells up to $124 \%$. The increased OD values at low chemical concentrations may reflect an increase of metabolic activity, due to cell-chemical interaction.

\section{Chemical Activity}

The percentages of biofilm reduction and inhibition by the chemical compounds are reported in Figures $\mathbf{4}$ and $\mathbf{5}$.

\section{Biofilm Degradation}

Dendrimers showed the highest biofilm reduction activity with both legionella mono-species and multi-species systems when compared to all other compounds (Figure 4). In general, G2 dendrimer was the most active in biofilm degradation, with statistically significant differences with relation to all compounds $(P<0.05)$, causing a reduction of $78 \%$ on $L$. pneumophila biofilm, while the highest decrease in multi-species biofilms was observed in L. pneumophila/P. aeruginosa (69\%) and L. pneumophila/E. coli (66\%). G0.5 dendrimer caused a similar reduction (63\%) only on L. pneumophila/P. aeruginosa biofilm.

Among the polyamino-phenolic compounds, Macrophen and Double Macrophen were overall the most effective chemicals, but no statistically significant differences were found $(P>0.05)$. In particular, Double Macrophen showed the highest reduction on L. pneumophila/E. coli biofilm (39\%), while Macrophen was the most effective on L. pneumophila/A. hydrophila and L. pneumophila/K. pneumonia (both 33\%). Macrophen, Double Macrophen and Dimo were the most efficacious compounds against $L$. pneumophila biofilm (27, 32, and $27 \%$ respectively).

\section{Biofilm Inhibition}

When biofilm formation inhibition was evaluated (Figure 5), dendrimers showed the highest inhibition activity, with statistically significant differences in relation to all other compounds $(P<0.05)$. G0.5 dendrimer was, overall, the compound that showed the best efficacy, abundantly inhibiting legionella mono-species (85\%) and L. pneumophila/A. hydrophila and L. pneumophila/E. coli (both 73\%) two-species biofilms. G2 dendrimer also caused a rather high biofilm inhibition, although less effective, on the same biofilms as G0.5 (61, 59,
$61 \%$ for L. pneumophila, L. pneumophila/A. hydrophila and L. pneumophila/E. coli biofilms respectively). Moreover, fivespecies biofilm was highly inhibited by G0.5 dendrimer, with a value of $68 \%$, more than twice as much as the other compounds.

Among the polyamino-phenolic ligands, Double Macrophen was the most effective on L. pneumophila biofilm (48\%). With respect to multi-species biofilms, Macrophen caused the highest inhibition on L. pneumophila/P. aeruginosa (26\%), L. pneumophila/K. pneumoniae (24\%) and five-species (27\%) biofilm formation, whereas Double Macrophen was the main inhibitor of L. pneumophila/A. hydrophila (34\%) and L. pneumophila/E. coli (42\%) biofilms.

\section{Planktonic Microbial Cell Viability after Chemical Treatment}

The most active chemicals (G2 and G0.5 dendrimers, Macrophen and Double Macrophen) against biofilms were selected to determine their antimicrobial activity on planktonic bacteria by flow cytometry. Viability test showed that Macrophen and Double Macrophen treatments did not reduce the number of viable cells in all microbial species, while G2 and G0.5 dendrimer treatments reduced the viability only in A. hydrophila (60 and $37 \%$ respectively) and E. coli (53 and 47\% respectively) (Figure 6 shows a representative dot plot), with a parallel increase in damaged cell number (Figure 7).

\section{Scanning Electron Microscopy}

The anti-biofilm activity of dendrimers was tested by SEM image analysis. After 3 days incubation, SEM revealed the formation of an abundant L. pneumophila 155 biofilm, extensively spread on the coverslip ( $1 \mathrm{~cm}$ diameter). Figures $\mathbf{8 A}, \mathbf{B}$ (control sample) shows bacteria adhering to the substrate and embedded in an extracellular matrix, clearly visible on the surface of the aggregated cells. In the treated samples no extracellular matrix is visible: naked bacteria, mainly forming a monolayer, are attached to the surface, but there is no connection between cells (Figure 8C). The presence of dendrimers caused the lack of extracellular matrix, resulting in the detachment of a relevant cell amount that may justify the high reduction percentages obtained in the biofilm inhibition assay.

\section{DISCUSSION}

Legionella pneumophila biofilm studies are usually carried out in culture media and at different incubation temperatures (Piao 


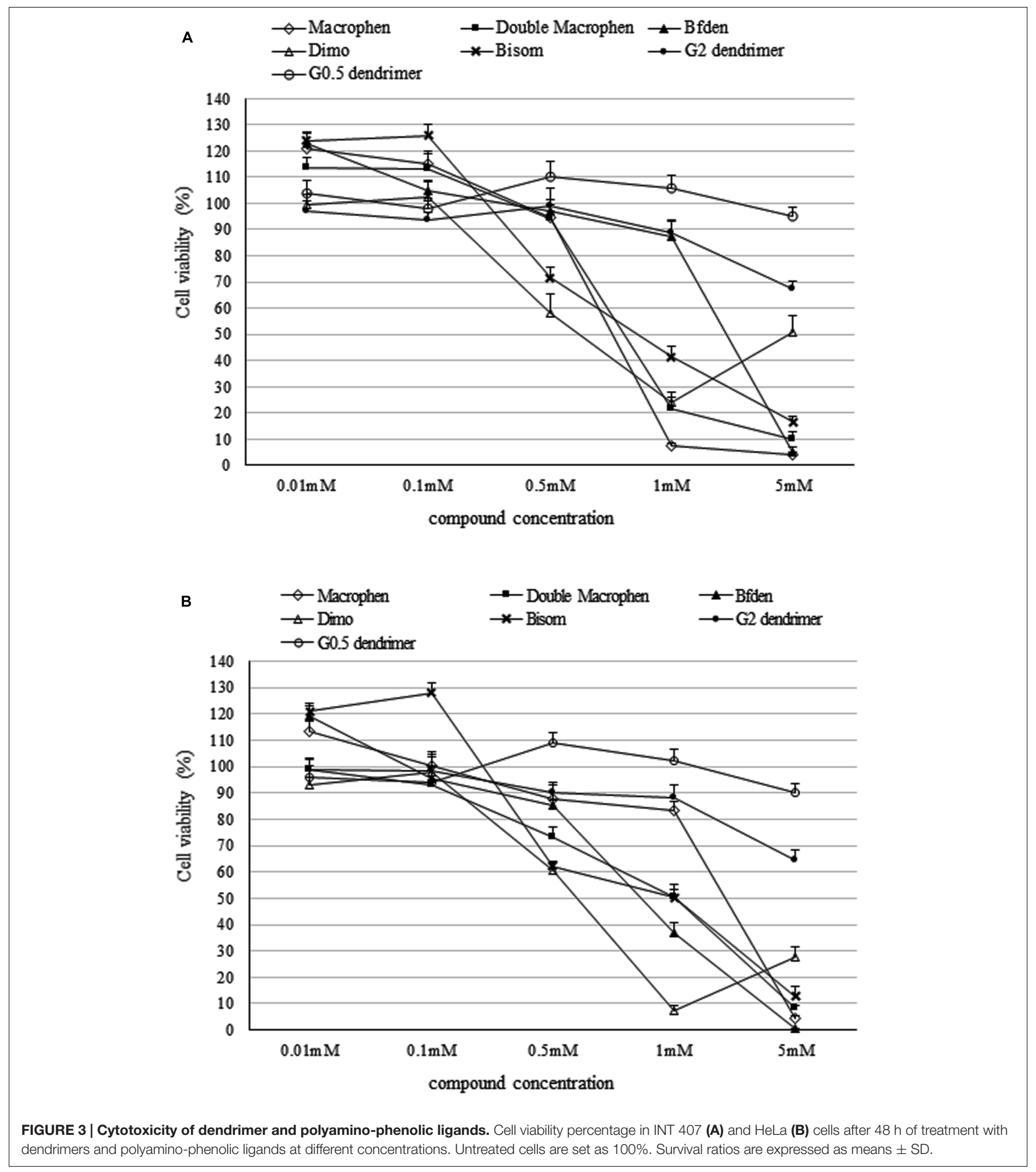

et al., 2006). Some projects, however, require experimental conditions more similar to the environment where bacteria are normally found. Investigation into chemical action against microbial biofilms is more reliable when conducted using environmental-like conditions. Hence, in this study filtered tap water was chosen as substrate to better mimic water-network environment, where these chemicals are expected to perform their action. Biofilms were formed at $37^{\circ} \mathrm{C}$ to support legionella survival and reproduce hot water system temperature, according to Portier and Héchard (2013). 


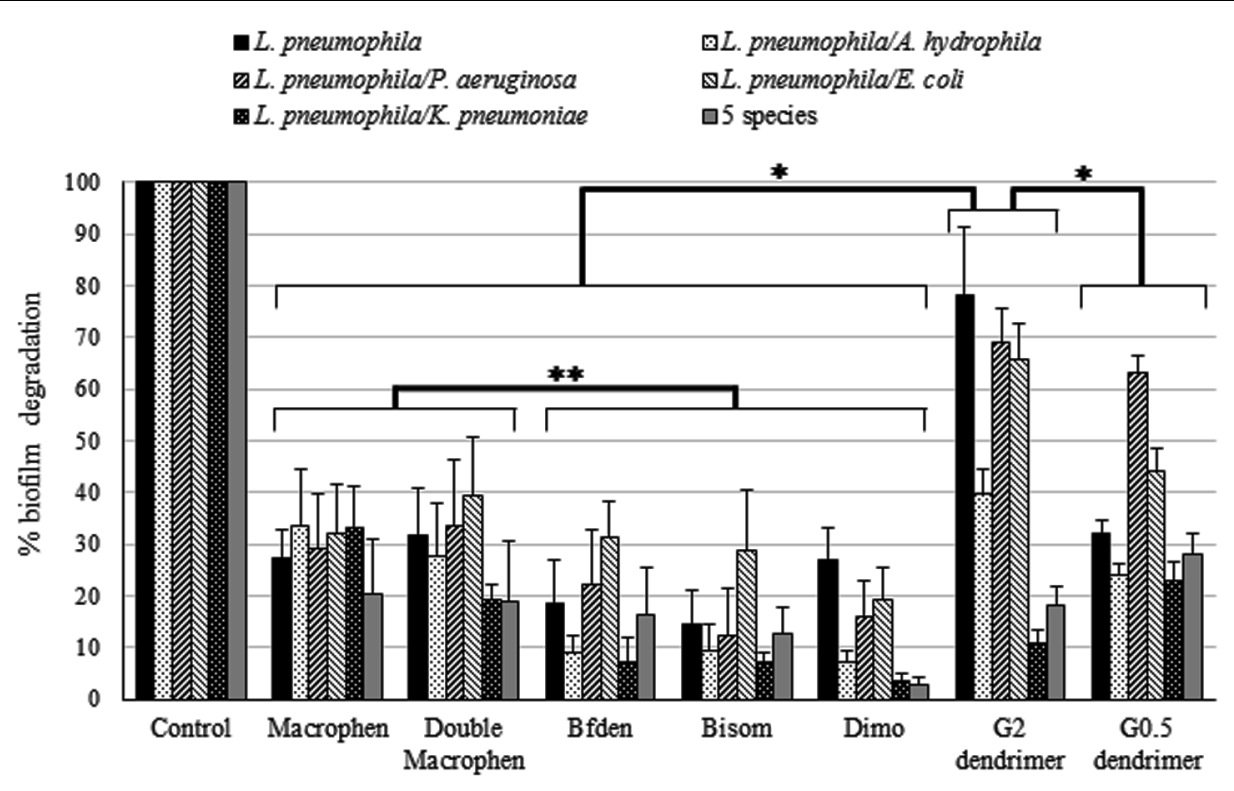

FIGURE 4 | Biofilm degradation activity of chemicals. Degradation of legionella mono-species and multi-species 3-day-old biofilms by chemicals. Biofilms were treated with $0.1 \mathrm{mM}$ polyamino-phenolic ligands and $1 \mathrm{mM}$ dendrimers after 3-day biofilm formation. Untreated biofilms were acted as controls (100\%). Degradation percentages are expressed as means $\pm \mathrm{SD}$. Asterisks indicate significant $\left({ }^{*} P<0.05\right)$ and non significant $(* * P>0.05)$ differences.

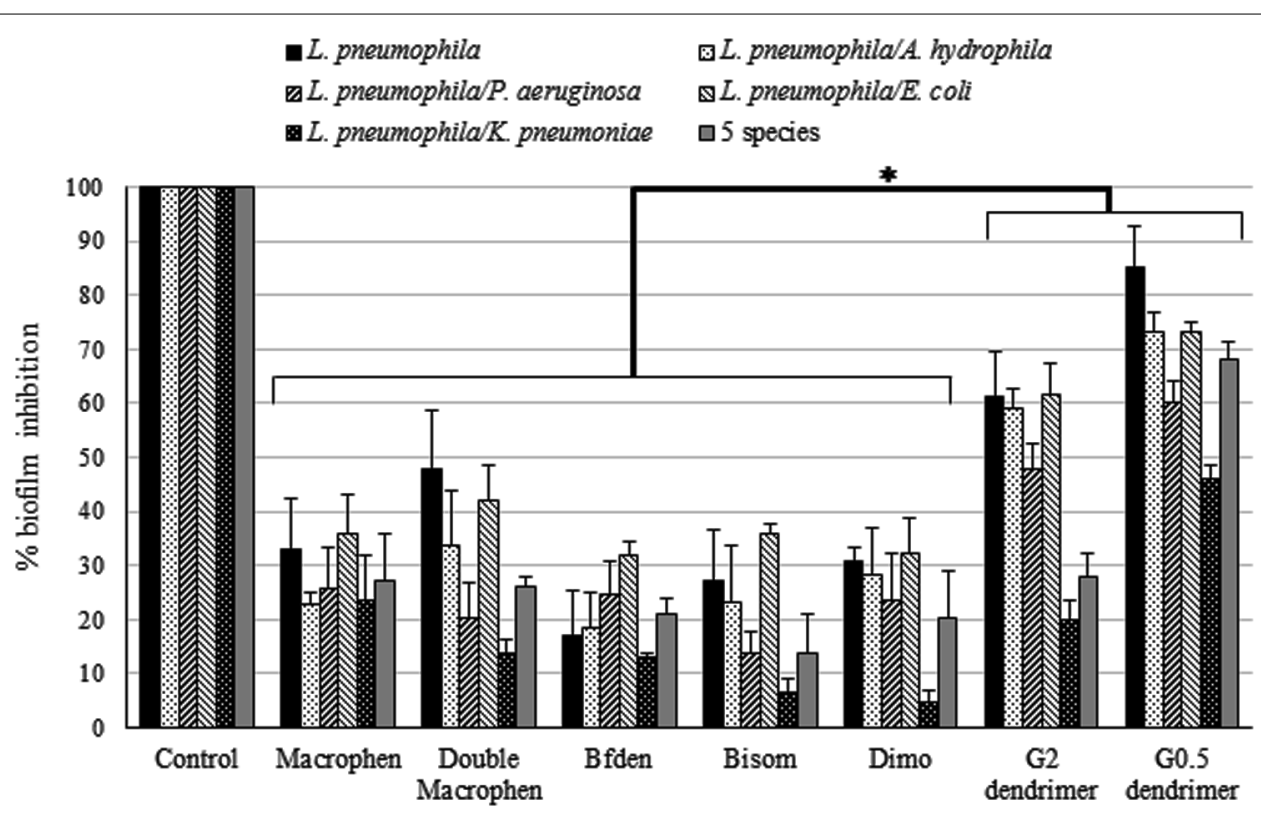

FIGURE 5 | Biofilm inhibition activity of chemicals. Inhibition of legionella mono-species and multi-species biofilm formation by chemicals. Biofilms were treated with $0.1 \mathrm{mM}$ polyamino-phenolic ligands and $1 \mathrm{mM}$ dendrimers during 3-day biofilm formation period. Untreated biofilms were acted as controls (100\%). Inhibition percentages are expressed as means $\pm \mathrm{SD}$. Asterisks indicate significant $(* P<0.05)$ differences.

Legionella pneumophila 155 was shown to be a biofilm producer both in BYE medium and in water based on the OD value obtained by Hucker's crystal violet assay. Moreover, demonstration of biofilm formation in water was confirmed by SEM, showing bacterial adhesion to surface and extracellular matrix connecting cells.
Pécastaings et al. (2010) demonstrated that L. pneumophila was able to form mono-species biofilm in low-nutrient medium not supporting planktonic growth and allowing bacterial replication only in the sessile phase, unlike classical rich media. Here, Legionella biofilm formation seemed not to be compromised in filtered water compared with culture media 

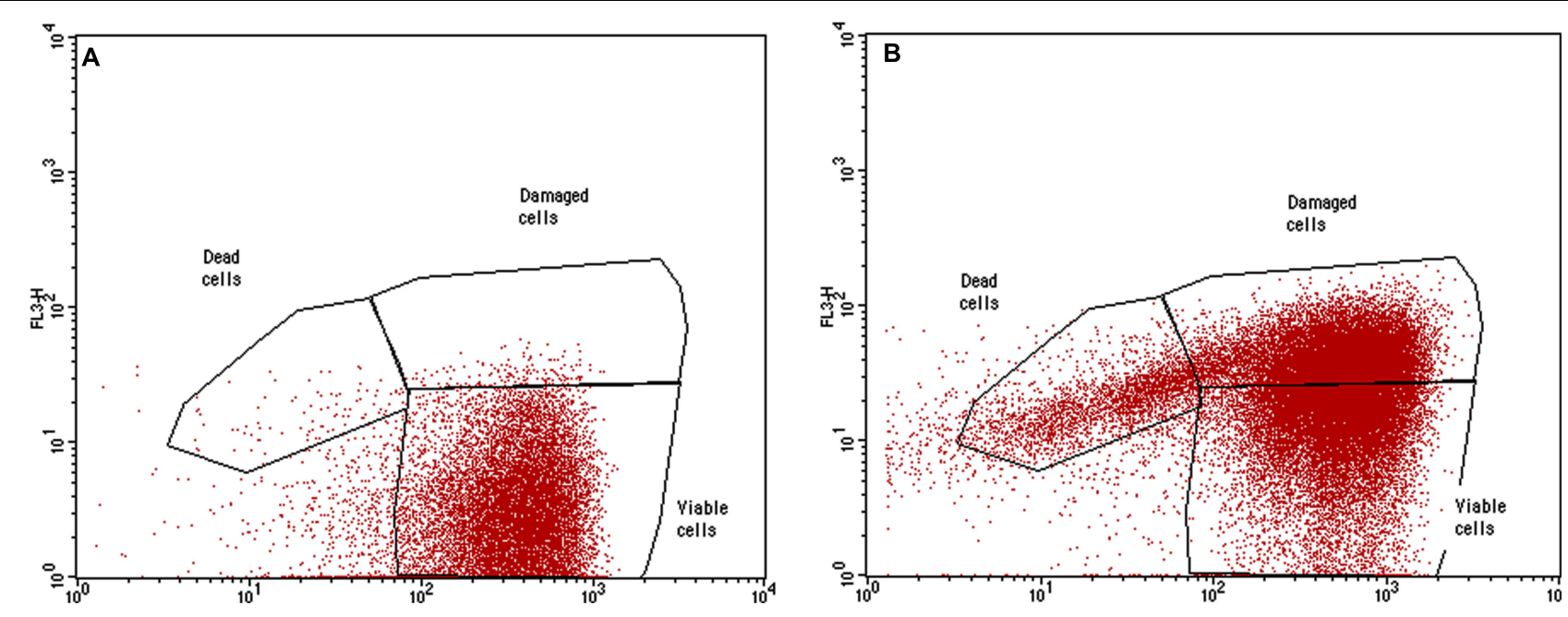

FIGURE 6 | Representative dot plot (FL1 vs. FL3). Planktonic E. coli cells labeled with SYBR Green I and PI treated with G2 dendrimer (B) respect to the untreated control (A).

after 3-day incubation. Matrix presence allows us to refer to a biofilm in the initial formation phase, even though its production was probably due to planktonic cell deposition rather then to cell replication. In fact, matrix production could result from the high initial bacterial inoculum that might determine the activation of the Quorum Sensing and, consequently, biofilm formation. However, matrix exopolysaccharides could act as source of nutrients, supporting bacteria survival and possible growth.

In experimental conditions mono-species biofilms show a higher reproducibility than multi-species biofilms. On the other hand, multi-species biofilm assays are necessary to investigate the actual chemical power in a model closer to the environment where the compounds should be used.

The formation of mixed biofilms was shown using Hucker's crystal violet assay, while the ability of viable bacteria to coexist were assessed by RTqPCR and CFU count assays. These methods were used only with the aim to verify the presence of viable bacteria; comparison between cell numbers of different bacterial species cannot be proposed because of the different quantification methods used (RTqPCR assay and CFU count) and the use of different selective media in CFU counts, that may vary in their ability to recover viable cells.

Interactions of different bacterial strains in mixed biofilms may turn into both synergy and reduction in biofilm production (Carpentier and Chassaing, 2004; Marouani-Gadri et al., 2009). Microbial interactions can determine appreciable biomass variation in two species biofilms in comparison with monospecies biofilms, and strains considered poor biofilm formers by themselves may be present in multi-species biofilms (Simões et al., 2007; Røder et al., 2015). Ren et al. (2015) also observed synergistic interactions with greater biofilm biomass production in multi-species communities compared with singlespecies cultures. Based on $\mathrm{CV}$ assay $\mathrm{OD}$ values, $K$. pneumoniae showed the highest synergistic effect (probably due to the positive interaction of the molecules involved in legionella and klebsiella Quorum Sensing mechanisms), proving to be the best species for L. pneumophila 155 to form biofilm with, followed by A. hydrophila. According to this result, Stewart et al. (2012) recently demonstrated that L. pneumophila is able to adhere and persist in K. pneumoniae dynamic biofilm. Considering bacteria that are not able to form biofilm, they could be able to adhere to an already formed biofilm or to other bacteria that have colonized a surface. In this study, $E$. coli and $P$. aeruginosa seem to be unable to form biofilm on their own, but biofilm formation happens in presence of L. pneumophila. They probably adhere to L. pneumophila cells, attached to the well surface, taking part in the biofilm biomass. L. pneumophila/E. coli biofilm OD is lower than L. pneumophila mono-species biofilm OD: in this case the presence of E. coli could slightly decrease L. pneumophila ability to produce biofilm. On the other hand L. pneumophila/P. aeruginosa biofilm OD is higher than L. pneumophila monospecies biofilm OD: it can be assumed that $P$. aeruginosa could enhance legionella ability to form biofilm.

In this work non-functionalized PAMAM dendrimers [strong antibacterial agents, less expensive and less tricky to be synthesized than the functionalized ones (Calabretta et al., 2007)] were used for the first time against Legionella biofilms. The efficacy of the chemicals not only to prevent bacteria from producing biofilms but also to reduce previously formed biofilms appeared to be dependent on the microorganism species and on the chemical properties. Overall, dendrimers were the molecules that generally reached the highest percentage of biofilm inhibition and reduction. It has to be pointed out that dendrimers were ten times more concentrated than polyaminophenolic ligands, due to the cytotoxicity results, and this could be the reason for the dendrimer best performance. Although polyamino-phenolic ligands could exhibit an increased efficacy at higher concentrations, chemical cytotoxicity has to be taken 


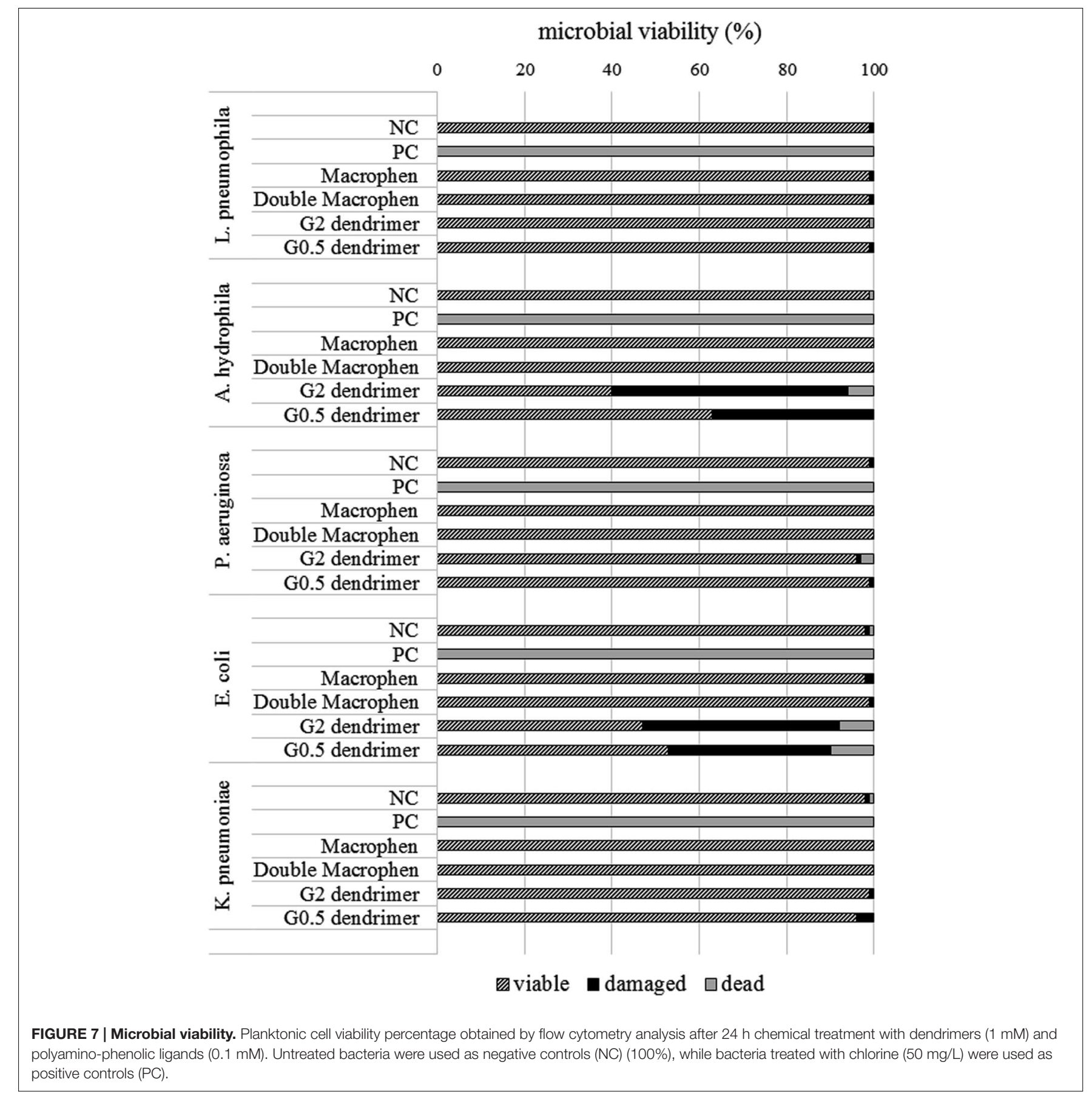

into account because it is a relevant feature when dealing with substances that could be used in water systems.

PAMAM dendrimers have been previously shown to be highly toxic to some bacteria: Calabretta et al. (2007) showed that G5 amino-terminated PAMAM dendrimer killed 50\% $\left(\right.$ EC $\left._{50}\right)$ of $P$. aeruginosa at concentrations of $1.5 \mu \mathrm{g} / \mathrm{mL}$; Lopez et al. (2009) also reported that the Minimum Inhibitory Concentration (MIC) values against $P$. aeruginosa were $6.3 \mu \mathrm{g} / \mathrm{mL}$ for $\mathrm{G} 3$ and $12.5 \mu \mathrm{g} / \mathrm{mL}$ for G5 PAMAM dendrimer, while the MIC values against Staphylococcus aureus were $12.5 \mu \mathrm{g} / \mathrm{mL}$ for both dendrimers. In our study, flow cytometric data revealed that both G2 and G0.5 dendrimers were able to decrease planktonic A. hydrophila and E. coli microbial viability, probably interacting with and damaging the bacterial outer membrane, while they were not microbicidal on planktonic L. pneumophila, $P$. aeruginosa, and K. pneumoniae, at the used concentration. Results regarding E. coli and $K$. pneumoniae agree with those by other authors (Xue et al., 2013), reporting that E. coli Minimum Bactericidal Concentration (MBC) ranges from 12.5 and $25 \mu \mathrm{g} / \mathrm{mL}$ for G2 dendrimer. On the contrary, results 


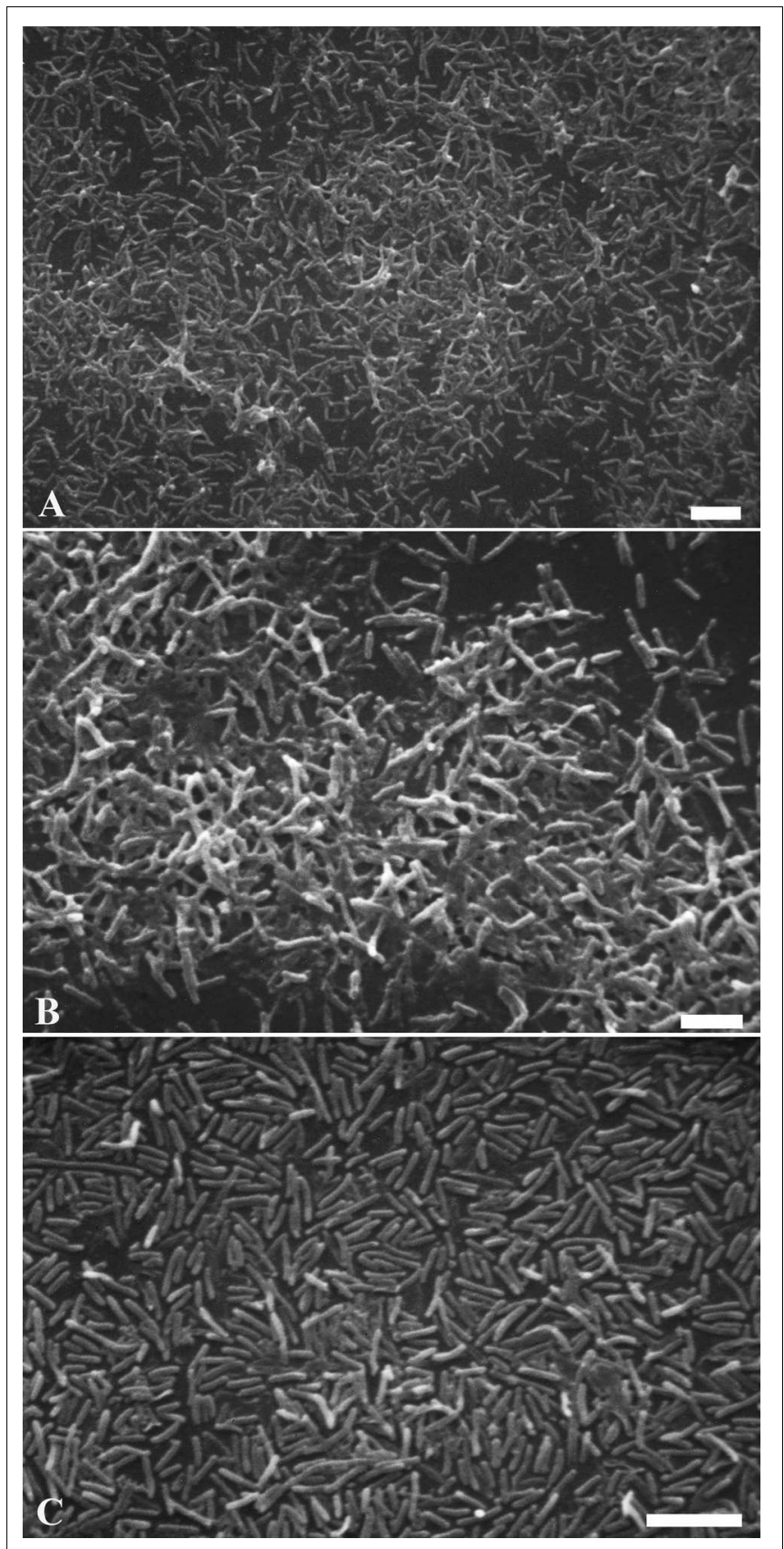

FIGURE 8 | Legionella pneumophila 155 biofilm scanning electron micrographs. Images showing biofilms formed by untreated $L$. pneumophila 155 cells (A,B) and L. pneumophila $155+\mathrm{G} 2$ dendrimer (1 mM) treatment (C). An abundant formation of diffuse masses of biofilm with extracellular matrix is visible in (A,B), while naked bacteria on the surface without extracellular matrix are shown in (C). (B) is a higher magnification of $(\mathbf{A})$. (A-C) Bar $=5 \mu \mathrm{m}$.

regarding $P$. aeruginosa contrast with literature data: Calabretta et al. (2007) referred that the $\mathrm{EC}_{50}$ for G5 PAMAM was about 170 -fold lower than the concentration used in our work, whereas Xue et al. (2013) showed that the MIC for G2 PAMAM was about 35-fold lower. The different effect of the dendrimers on the same bacterial species may be due to the different behavior of the single strains, but also to the different bacterial concentrations used in various studies. To the best of our knowledge, data concerning L. pneumophila and A. hydrophila has not been reported yet.

Non-functionalized PAMAM dendrimers act through nonspecific mechanisms, unlike functionalized dendrimers, acting through specific molecule interactions (Calabretta et al., 2007; Wang et al., 2010; Xue et al., 2013). Cationic amine groups on full-generation dendrimer (such as PAMAM G2) surface may favor the adsorption onto negatively charged bacterial wall by electrostatic attraction, and change membrane permeability eventually resulting in cell death (Calabretta et al., 2007; Tülü and Ertürk, 2012; Xue et al., 2013); particularly, in gramnegative bacteria the polycation dendrimer may bind the polyanion lipopolysaccharide (replacing the stabilizing divalent ions, calcium and magnesium), may diffuse through the cell wall and destroy the inner cytoplasmic membrane. Also halfgeneration carboxyl terminated dendrimers (such as PAMAM G0.5) may alter the structure and permeability of the bacterial outer membrane acting as a polyanion chelating calcium and magnesium ions (which bind and stabilize the phosphate group in the lipid layer) and leading to cell wall disruption (Wang et al., 2010).

In this study, despite the lack of microbicidal activity in the majority of plancktonic bacteria, dendrimers were overall highly active against biofilms, suggesting that the anti-biofilm efficacy was not mainly due to the chemical microbicidal activity. Bacterial adhesion, the initial phase of biofilm formation, could be limited by dendrimer interaction with cell surface or with ions (that promote microbial adhesion), changing wall properties and avoiding microbial attachment to the substrate. However, the lack of microbicidal activity might suggest that biofilm inhibition by dendrimers was more likely to be due to chemical interaction with bonds and differently charged molecules in the matrix than with bacterial cells. This hypothesis was also confirmed by SEM images showing that L. pneumophila 155 biofilm treated with dendrimers was lacking in extracellular matrix; dendrimers could prevent the molecules produced by legionellae from binding to form the extracellular polymeric substances (EPS) of the matrix, weakening the adhesion of the cells to the surface and cell to cell interaction. Nevertheless, these hypotheses have to be confirmed by further analysis on dendrimer mechanisms of action.

Polyamino-phenolic ligands showed a lower anti-biofilm activity compared to dendrimer action at the concentrations used, even if they also caused biofilm inhibition and degradation, especially Macrophen and Double Macrophen on mono-species biofilms. Polyamino-phenolic ligands can act as chelating agents, forming complexes with cations, such as calcium and magnesium. Deficiency in these divalent ions might destabilize the biofilm matrix, usually constituted by proteins, extracellular DNA and especially polysaccharides (Branda et al., 2005), which normally bind a large amount of cations, whose lack may damage the biofilm structure and cause its detachment (Turakhia et al., 1983). Furthermore, the interaction with the extracellular matrix is more likely than the interaction with bacterial wall, because of the lack of Macrophen and Double Macrophen microbicidal activity. 
Our work shows for the first time the reduction efficiency of polyamino-phenolic ligands and G2 and G0.5 PAMAM dendrimers on L. pneumophila biofilms in the initial stage of their formation in filtered tap water. In particular, dendrimers were the most effective compounds, thanks to their lower cytotoxicity that allowed the use of a higher concentration. The anti-biofilm activity was not achieved by chemical antimicrobial properties, but probably by chemical interaction with the electrostatic bonds present in the biofilm that allowed the partial detachment.

These data suggest that the studied compounds, especially dendrimers, could be seen as potentially interesting molecules that might be studied for a possible rule in support of new efficacious anti-biofilm disinfection treatments, releasing bacteria, as Legionella sp., from protective biofilms, making microorganisms susceptible to disinfectant concentrations usually used in water systems. Nevertheless, further experiments are needed to study biofilm inhibition efficacy in presence of protozoa and at different chemical concentrations and incubation times to identify the time required to obtain the maximum biofilm reduction not only in static but also in dynamic flow conditions. Furthermore, the study of the interaction of these compounds with the biofilm is crucial to better understand the mechanism of action that allows them to inhibit bacterial attachment or promote matrix detachment.

\section{AUTHOR CONTRIBUTIONS}

EA and AP conceived and designed the experiments. EA, FB, and LS performed the experiments. EA analyzed the data. MO made the dendrimers available for usage, was involved in the writing of the chemical description and dispensed helpful advice for dendrimer usage. LG sinthetized polyamino-phenolic ligands,

\section{REFERENCES}

Ambrosi, G., Formica, M., Fusi, V., Giorgi, L., and Micheloni, M. (2008). Polynuclear metal complexes of ligands containing phenolic units. Coordin. Chem. Rev. 252, 1121-1152. doi: 10.1016/j.ccr.2007.09.027

Andreozzi, E., Di Cesare, A., Sabatini, L., Chessa, E., Sisti, D., Rocchi, M., et al. (2014). Role of biofilm in protection of the replicative form of Legionella pneumophila. Curr. Microbiol. 69, 769-774. doi: 10.1007/s00284-0140648-y

Baldassarri, L., Cecchini, R., Bertuccini, L., Ammendolia, M. G., Iosi, F., Arciola, C. R., et al. (2001). Enterococcus spp. produces slime and survives in rat peritoneal macrophages. Med. Microbiol. Immunol. 190, 113-120.

Banin, E., Brady, K. M., and Greenberg, E. P. (2006). Chelator-induced dispersal and killing of Pseudomonas aeruginosa cells in a biofilm. Appl. Environ. Microbiol. 72, 2064-2069. doi: 10.1128/AEM.72.3.2064-2069.2006

Bartram, J., Chartier, Y., Lee, J. V., Pond, K., and Surman-Lee, S. (2007). Legionella and the Prevention of Legionellosis. Geneva: World Health Organization.

Battistelli, M., De Sanctis, R., De Bellis, R., Cucchiarini, L., Dachà, M., and Gobbi, P. (2005). Rhodiola rosea as antioxidant in red blood cells: ultrastructural and hemolytic behavoiur. Eur. J. Histochem. 49, 243-254.

Boi, P., Manti, A., Pianetti, A., Sabatini, L., Sisti, D., Rocchi, M. B., et al. (2015). Evaluation of Escherichia coli viability by flow cytometry: a method for determining bacterial responses to antibiotic exposure. Cytometry B Clin. Cytom. 88, 149-153. doi: 10.1002/cyto.b.21214

Branda, S. S., Vik, A., Friedman, L., and Kolter, R. (2005). Biofilms: the matrix revisited. Trends Microbiol. 13, 20-26. doi: 10.1016/j.tim.2004.11.006 was involved in the writing of the chemical description and dispenced helpful advice for polyamino-phenolic ligand usage. AM supplied cytometry analysis tools and methods, was involved in sample cytometric analysis and in the writing of the cytometric section. MB supplied SEM analysis tools and methods and was involved in SEM image capture. EA wrote the paper. AP and FB were involved in the writing and review of the article. AP and FB managed founds. All authors have approved the final version of the article. All authors agree to be accountable for all aspects of the work in ensuring that questions related to the accuracy or integrity of any part of the work are appropriately investigated and resolved.

\section{FUNDING}

This study was partly supported by "Fondazione Cassa Di Risparmio di Pesaro."

\section{ACKNOWLEDGMENTS}

We thank Francesco Marinelli, Doctor in Statistical Science (University of Bologna, Italy), for his collaboration in the statistical analysis. We would like to acknowledge Prof. Donald A. Tomalia (NanoSynthons LLC, The National Dendrimer and Nanotechnology Center, Mt. Pleasant), for kindly providing the PAMAM dendrimers. We are grateful to Marina Pecellin, who was involved in the 16S rRNA gene sequencing, and Prof. Dr. Manfred Höfle, (Helmholtz Centre for Infection Research, Braunschweig, Germany), for kindly authorizing the publication of the sequencing data. We wish to thank Rui P. A. Pereira for the reviewing of the manuscript and helpful comments.

Bridier, A., Briandet, R., Thomas, V., and Dubois-Brissonnet, F. (2011). Resistance of bacterial biofilms to disinfectants: a review. Biofouling 27, 1017-1032. doi: 10.1080/08927014.2011.626899

Calabretta, M. K., Kumar, A., McDermott, A. M., and Cai, C. (2007). Antibacterial activities of poly(amidoamine) dendrimers terminated with amino and poly(ethylene glycol) groups. Biomacromolecules 8, 1807-1811. doi: 10.1021/bm0701088

Carpentier, B., and Chassaing, D. (2004). Interactions in biofilms between Listeria monocytogenes and resident microorganisms from food industry premises. Int. J. Food Microbiol. 97, 111-122. doi: 10.1016/j.ijfoodmicro.2004. 03.031

Chang, Y., Gu, W., and McLandsborough, L. (2012). Low concentration of ethylenediaminetetraacetic acid (EDTA) affects biofilm formation of Listeria monocytogenes by inhibiting its initial adherence. Food Microbiol. 29, 10-17. doi: 10.1016/j.fm.2011.07.009

Chen, Z. C., and Cooper, S. L. (2000). Recent advances in antimicrobial dendrimers. Adv. Mater. 12, 843-846. doi: 10.1002/(SICI)15214095(200006)12:11<843::AID-ADMA843>3.3.CO;2-K

Cole, J. R., Wang, Q., Fish, J. A., Chai, B., McGarrell, D. M., Sun, Y., et al. (2013). Ribosomal database project: data and tools for high throughput rRNA analysis. Nuclic Acids Res. 42, D633-D642. doi: 10.1093/nar/gkt1244

Cooper, I. R., and Hanlon, G. W. (2010). Resistance of Legionella pneumophila serotype 1 biofilms to chlorine-based disinfection. J. Hosp. Infect. 74, 152-159. doi: 10.1016/j.jhin.2009.07.005

de Carvalho, C. C. C. R. (2007). Biofilms: recent developments on an old battle. Recent Pat. Biotechnol. 1, 49-57. doi: 10.2174/187220807779813965 
Declerck, P., Behets, J., Margineanu, A., van Hoef, V., De Keersmaecker, B., and Ollevier, F. (2009). Replication of Legionella pneumophila in biofilms of water distribution pipes. Microbiol. Res. 164, 593-603. doi: 10.1016/j.micres.2007.06.001

DeLong, E. F. (1992). Archaea in coastal marine environments. Proc. Natl. Acad. Sci. U.S.A. 89, 5685-5689. doi: 10.1073/pnas.89.12.5685

Ditommaso, S., Biasin, C., Giacomuzzi, M., Zotti, C. M., Cavanna, A., and Ruggenini Moiraghi, A. (2005). Peracetic acid in the disinfection of a hospital water system contaminated with Legionella species. Infect. Control. Hosp. Epidemiol. 26, 490-493. doi: 10.1086/502573

Doleans, A., Aurell, H., Reyrolle, M., Lina, G., Freney, J., Vandenesch, F. J., et al. (2004). Clinical and environmental distributions of Legionella strains in France are different. J. Clin. Microbiol. 42, 458-460. doi: 10.1128/JCM.42.1.458460.2004

Guidelines for prevention and control of legionellosis (2000). "Linee-guida per la prevenzione e il controllo della legionellosi," in Proceedings of the Permanent Conference for the Relationship Between the Government, the Regions, Trento and Bolzano, 103.

Hou, S., Zhou, C., Liu, Z., Young, A. W., Shi, Z., Ren, D., et al. (2009). Antimicrobial dendrimer active against Escherichia coli biofilms. Bioorg. Med. Chem. Lett. 19, 5478-5481. doi: 10.1016/j.bmcl.2009.07.077

Iatta, R., Cuna, T., Napoli, C., De Giglio, O., and Montagna, M. T. (2013). Environmental surveillance and molecular investigation of Legionella spp. in Apulia, in the years 2008-2011. Ann. Ig. 25, 435-441.

Jakubek, D., Le Brun, M., Leblon, G., DuBow, M., and Binet, M. (2013). The impact of monochloramine on the diversity and dynamics of Legionella pneumophila subpopulations in a nuclear power plant cooling circuit. FEMS Microbiol. Ecol. 85, 302-312. doi: 10.1111/1574-6941.12121

Johansson, E. M. V., Crusz, S. A., Kolomiets, E., Buts, L., Kadam, R. U., Cacciarini, M., et al. (2008). Inhibition and dispersion of Pseudomonas aeruginosa biofilms by glycopeptide dendrimers targeting the fucose-specific lectin, LecB. Chem. Biol. 15, 1249-1257. doi: 10.1016/j.chembiol.2008. 10.009

Kahlisch, L., Henne, K., Draheim, J., Brettar, I., and Höfle, M. G. (2010). High-resolution in situ genotyping of Legionella pneumophila populations in drinking water by multiple-locus variable-number tandem-repeat analysis using environmental DNA. Appl. Environ. Microbiol. 76, 6186-6195. doi: 10.1128/AEM.00416-10

Khan, M. A., Knox, N., Prashar, A., Alexander, D., Abdel-Nour, M., Duncan, C., et al. (2013). Comparative genomics reveal that host-innate immune responses influence the clinical prevalence of Legionella pneumophila serogroups. PLoS ONE 8:e67298. doi: 10.1371/journal.pone.0067298

Khweek, A. A., Fernández Dávila, N. S., Caution, K., Akhter, A., Abdulrahman, B. A., Tazi, M., et al. (2013). Biofilm-derived Legionella pneumophila evades the innate immune response in macrophages. Front. Cell. Infect. Microbiol. 3:18. doi: $10.3389 /$ fcimb. 2013.00018

Klajnert, B., Cladera, J., and Bryszewska, M. (2006). Molecular interactions of dendrimers with amyloid peptides: $\mathrm{pH}$ dependence. Biomacromolecules 7 , 2186-2191. doi: 10.1021/bm060229s

Lane, D. J. (1991). "16S/23S rRNA sequencing," in Nucleic Acid Techniques in Bacterial Systematics, eds E. Stackebrandt and M. Goodfellow (New York, NY: Wiley), 115-175.

Lau, H. Y., and Ashbolt, N. J. (2009). The role of biofilms and protozoa in Legionella pathogenesis: implications for drinking water. J. Appl. Microbiol. 107, 368-378. doi: 10.1111/j.1365-2672.2009.04208.x

Lazniewska, J., Milowska, K., and Gabryelak, T. (2012). Dendrimers - revolutionary drugs for infectious diseases. WIREs Nanomed Nanobiotechnol. 4, 469-491. doi: 10.1002/wnan. 1181

Levin, A. S. (2009). Nosocomial legionellosis: prevention and management. Exp. Rev. Anti-Infect. Ther. 7, 57-68. doi: 10.1586/14787210.7.1.57

Lopez, A. I., Reins, R. Y., McDermott, A. M., Trautner, B. W., and Cai, C. (2009). Antibacterial activity and cytotoxicity of pegylated poly(amidoamine) Dendrimers. Mol. BioSyst. 5, 1148-1156. doi: 10.1039/b90 $4746 \mathrm{~h}$

Manti, A., Boi, P., Amalfitano, S., Puddu, A., and Papa, S. (2011). Experimental improvements in combining CARD-FISH and flow cytometry for bacterial cell quantification. J. Microbiol. Methods 87, 309-315. doi: 10.1016/j.mimet.2011.09.003
Marouani-Gadri, N., Augier, G., and Carpentier, B. (2009). Characterization of bacterial strains isolated from a beef-processing plant following cleaning and disinfection - influence of isolated strains on biofilm formation by Sakaï and EDL 933 E. coli O157:H7. Int. J. Food Microbiol. 133, 62-67. doi: 10.1016/j.ijfoodmicro.2009.04.028

Messi, P., Bargellini, A., Anacarso, I., Marchesi, I., de Niederhäusern, S., and Bondi, M. (2013). Protozoa and human macrophages infection by Legionella pneumophila environmental strains belonging to different serogroups. Arch. Microbiol. 195, 89-96. doi: 10.1007/s00203-0120851-9

Miyamoto, M., Yamaguchi, Y., and Sasatsu, M. (2000). Disinfectant effects of hot water, ultraviolet light, silver ions and chlorine on strains of Legionella and nontuberculous Mycobacteria. Microbios 101, 7-13.

Ng, V., Tang, P., Jamieson, F., Guyard, C., Low, D. E., and Fisman, D. N. (2009). Laboratory-based evaluation of legionellosis epidemiology in Ontario, Canada, 1978 to 2006. BMC Infect. Dis. 9:68-77. doi: 10.1186/1471-23 34-9-68

Osawa, K., Shigemura, K., Abe, Y., Jikimoto, T., Yoshida, H., Fujisawa, M., et al. (2014). A case of nosocomial Legionella pneumonia associated with a contaminated hospital cooling tower. J. Infect. Chemother.9:68. doi: 10.1016/j.jiac.2013.07.007

Ottaviani, D., Parlani, C., Citterio, B., Masini, L., Leoni, F., Canonico, C., et al. (2011). Putative virulence properties of Aeromonas strains isolated from food, environmental and clinical sources in Italy: a comparative study. Int. J. Food Microbiol. 144, 538-545. doi: 10.1016/j.ijfoodmicro.2010. 11.020

Ottaviani, M. F., Furini, F., Casini, A., Turro, N. J., Jockusch, S., Tomalia, D. A., et al. (2000). Formation of supramolecular structures between DNA and starburst dendrimers studied by EPR, CD, UV and melting profiles. Macromolecules 33, 7842-7851. doi: 10.1021/ma000877i

Ottaviani, M. F., Jockusch, S., Turro, N. J., Tomalia, D. A., and Barbon, A. (2004). Interactions of dendrimers with selected amino acids and proteins studied by Continuous Wave EPR and Fourier Transform EPR. Langmuir 20, 10238-10245. doi: 10.1021/la0485881

Pécastaings, S., Bergé, M., Dubourg, K. M., and Roques, C. (2010). Sessile Legionella pneumophila is able to grow on surfaces and generate structured monospecies biofilms. Biofouling 26, 809-819. doi: 10.1080/08927014.2010.520159

Piao, Z., Sze, C. C., Barysheva, O., Iida, K., and Yoshida, S. (2006). Temperatureregulated formation of mycelial mat-like biofilms by Legionella pneumophila. Appl. Environ. Microbiol. 72, 1613-1622. doi: 10.1128/AEM.72.2.16131622.2006

Portier, E., and Héchard, Y. (2013). "Natural biofilm formation with Legionella pneumophila," in Legionella: Methods and Protocols. Methods in Molecular Biology, eds C. Buchrieser and H. Hilbi (New York, NY: Springer Science \& Buisness Media), 213-217.

Qasem, J. A., Mustafa, A. S., and Khan, Z. U. (2008). Legionella in clinical specimens and hospital water supply facilities: molecule, detection and genotyping of the isolates. Med. Princ. Pract. 17, 49-55. doi: 10.1159/0001 09590

Ren, D., Madsen, J. S., Sørensen, S. J., and Burmølle, M. (2015). High prevalence of biofilm synergy among bacterial soil isolates in cocultures indicates bacterial interspecific cooperation. ISME J. 9, 81-89. doi: 10.1038/ismej.2014.96

Røder, H. L., Raghupathi, P. K., Herschend, J., Brejnrod, A., Knøchel, S., Sørensen, S. J., et al. (2015). Interspecies interactions result in enhanced biofilm formation by co-cultures of bacteria isolated from a food processing environment. Food Microbiol. 51, 18-24. doi: 10.1016/j.fm.2015.04.008

Sabatini, L., Pianetti, A., Cecchetti, G., Bruner, A., Citterio, B., Barbieri, F., et al. (2013). Chemical and microbiological monitoring of air in two waste incineration plants. Ig Sanita Pubbl. 69, 13-37.

Sanli-Yurudu, N. O., Kimiran-Erdem, A., and Cotuk, A. (2007). Studies on the efficacy of chloramine $\mathrm{T}$ trihydrate (N-chloro-p-toluene sulfonamide) against planktonic and sessile populations of different Legionella pneumophila strains. Int. J. Hyg. Environ. Health 210, 147-153. doi: 10.1016/j.ijheh.2006.08.004

Simões, L. C., Simões, M., and Maria João Vieira, M. J. (2007). Biofilm interactions between distinct bacterial genera isolated from drinking water. Appl. Environ. Microbiol. 73, 6192-6200. doi: 10.1128/AEM.00837-07

Steed, J. W., and Atwood, J. L. (2009). Supramolecular Chemistry, 2nd Edn. Hoboken, NJ: John Wiley \& Sons, Ltd. 
Steinert, M., Hentschel, U., and Hacker, J. (2002). Legionella pneumophila: an aquatic microbe goes astray. FEMS Microbiol. Rev. 26, 149-162. doi: 10.1111/j.1574-6976.2002.tb00607.x

Stewart, C. R., Muthye, V., and Cianciotto, N. P. (2012). Legionella pneumophila persists within biofilms formed by Klebsiella pneumoniae, Flavobacterium sp., and Pseudomonas fluorescens under dynamic flow conditions. PLoS ONE 7:e50560. doi: 10.1371/journal.pone.0050560

Taj, Y., Essa, F., Aziz, F., and Kazmi, S. U. (2012). Study on biofilm-forming properties of clinical isolates of Staphylococcus aureus. J. Infect. Dev. Ctries 6, 403-409. doi: 10.3855/jidc. 1743

Tiwari, W., Roy, R., and Tiwari, M. (2015). Antimicrobial active herbal compounds against Acinetobacter baumannii and other pathogens. Front. Microbiol. 6:18. doi: $10.3389 /$ fmicb. 2015.00618

Tomalia, D. A., Christensen, J. B., and Boas, U. (2012). Dendrimers, Dendrons, and Dendritic Polymers: Discovery, Applications, and the Future. Cambridge: Cambridge University Press.

Tülü, M., and Ertürk, A. S. (2012). "Dendrimers as antibacterial agents," in A Search for Antibacterial Agents, ed. V. Bobbarala (Rijeka: InTech), 89-106.

Turakhia, M. H., Cooksey, K. E., and Characklis, W. G. (1983). Influence of a calcium-specific chelant on biofilm removal. Appl. Environ. Microbiol. 46, 1236-1238.

Wang, B., Navath, R. S., Menjoge, A. R., Balakrishnan, B., Bellair, R., Dai, H., et al. (2010). Inhibition of bacterial growth and intramniotic infection in a guinea pig model of chorioamnionitis using PAMAM dendrimers. Int. J. Pharm. 395, 298-308. doi: 10.1016/j.ijpharm.2010.05.030
Watnick, P., and Kolter, R. (2000). Biofilm, city of microbes. J. Bacteriol. 182, 2675-2679. doi: 10.1128/JB.182.10.2675-2679.2000

Xue, X., Chen, X., Mao, X., Hou, Z., Zhou, Y., Bai, H., et al. (2013). Aminoterminated generation 2 poly(amidoamine) dendrimer as a potential broadspectrum, nonresistance-inducing antibacterial agent. AAPS J. 15, 132-142. doi: 10.1208/s12248-012-9416-8

Zarena, A. S., and Gopal, S. (2013). Dendrimer a new dimension in targeting biofilms. Mini-Rev. Med. Chem. 13, 1448-1461. doi: 10.2174/13895575113139990064

Zhang, Y. Q., Ren, S. X., Li, H. L., Wang, Y. X., Fu, G., Yang, J., et al. (2003). Genome-based analysis of virulence genes in a non-biofilm-forming Staphylococcus epidermidis strain (ATCC 12228). Mol. Microbiol. 49, 15771593. doi: 10.1046/j.1365-2958.2003.03671.x

Conflict of Interest Statement: The authors declare that the research was conducted in the absence of any commercial or financial relationships that could be construed as a potential conflict of interest.

Copyright (C) 2016 Andreozzi, Barbieri, Ottaviani, Giorgi, Bruscolini, Manti, Battistelli, Sabatini and Pianetti. This is an open-access article distributed under the terms of the Creative Commons Attribution License (CC BY). The use, distribution or reproduction in other forums is permitted, provided the original author(s) or licensor are credited and that the original publication in this journal is cited, in accordance with accepted academic practice. No use, distribution or reproduction is permitted which does not comply with these terms. 